\title{
The periodic health examination in adults
}

\section{David Ponka MDCM MSc (Int Prim Care)}

\section{Traditionally, the periodic health examination has comprised an annual visit} to a doctor for screening and preventive purposes

The origins of the periodic health examination (PHE) date back to at least the industrial revolution, when employers paid for annual check-ups to keep their labour forces healthy. Today, the practice is subsumed into the work of primary care physicians and is still widespread throughout Canada. It is referred to by different terms (e.g., annual health examination, periodic health visit) and is not an insured service in all provinces. ${ }^{1}$

Potential advantages of the PHE include performance of preventive manoeuvres

The PHE is an opportunity to perform evidence-based preventive manoeuvres, to counsel patients on lifestyle issues, update vaccinations and, importantly, to identify risk factors and diagnoses through updating the cumulative patient profile (i.e., patient history). ${ }^{3,4}$ However, this may not be necessary annually in patients at low risk. For resources on preventive manoeuvres, see Appendix 1 (available at www.cmaj.ca/lookup/suppl /doi:10.1503/cmaj.141125/-/DC1).
The PHE has not been shown to reduce morbidity and mortality

A Cochrane systematic review found no evidence of an impact on patient outcomes. ${ }^{5}$ Furthermore, PHEs may lead to too many blood tests, chest radiographs and electrocardiograms, exposing patients to the risks of investigation, such as false-positive results and overdiagnosis ${ }^{5}$ (Box 1). Populationbased preventive efforts may be more effective at reducing morbidity and mortality.

\section{Box 1: Choosing Wisely Canada recommendations on periodic health} examinations ${ }^{6}$

- Don't do annual screening blood tests unless directly indicated by the risk profile of the patient.

- Don't order screening chest radiographs and electrocardiograms for asymptomatic or low-risk outpatients.
CMAJ is collaborating with Choosing Wisely Canada (choosingwiselycanada.org), with support from Health Canada, to publish a series of articles describing how to apply the Choosing Wisely Canada recommendations in clinical practice.
The value of the PHE in adults is unclear

Some countries, such as the United Kingdom and Germany, encourage PHEs for otherwise healthy adults aged 40-75 years, arguing that these groups have an increasing burden of lifestyle and chronic diseases that may be amenable to intervention. ${ }^{2}$ In Canada, however, the ongoing variability in practice, with a trend toward reducing or eliminating the use of PHEs in adults, may be confusing to patients.

The value of a regular (not necessarily annual) PHE may lie in other factors

The PHE may serve as a mechanism to assist marginalized groups who would otherwise not attend regularly. ${ }^{3}$ It may also facilitate efforts around management of chronic disease and deprescribing. The patient-doctor relationship itself is increasingly being shown to affect health outcomes. ${ }^{7}$ However, sustained, relationship-based care may be possible only by reducing other, unnecessary, visits.

See references, www.cmaj.ca/lookup/suppl /doi:10.1503/cmaj.141125/-/DC1

\section{Competing interests: None declared.}

This article has been peer reviewed.

Affiliation: Department of Family Medicine, University of Ottawa, Ottawa, Ont.

Correspondence to: David Ponka, dponka @ bruyere.org

CMAJ 2014. DOI:10.1503/cmaj.141125 